\title{
BIOSENSORS
}

\section{Extraction and Detection of Pesticides by Cholinesterase Inhibition in a Two-Phase System: a Strategy to Avoid Heavy Metal Interference}

\author{
Fabiana Arduini and Francesco Ricci \\ Dipartimento di Scienze e Tecnologie Chimiche, Università di Roma \\ Tor Vergata, Via della Ricerca Scientifica, Rome, Italy \\ Ilhame Bourais and Aziz Amine \\ Faculté des Sciences et Techniques de Mohammedia, Morocco \\ Danila Moscone and Giuseppe Palleschi \\ Dipartimento di Scienze e Tecnologie Chimiche, Università di Roma \\ Tor Vergata, Via della Ricerca Scientifica, Rome, Italy
}

\begin{abstract}
A novel method of extraction has been developed to avoid the presence of heavy metals during the measurement of pesticides based on acetylcholinesterase (AchE) inhibition. Heavy metals have been in fact demonstrated in this article to interfere when the assay is performed by using the classic spectrophotometric Ellman's method. We present the results obtained with an assay system using two different phases, one organic and the other aqueous, in which the pesticide and the enzyme are, respectively, solubilized. In a first step, the concentration of the substrate acetylthiocholine $(1 \mathrm{mM})$, of the enzyme $\left(7 \mathrm{mU} \mathrm{mL}{ }^{-1}\right)$, and the reaction time $(20 \mathrm{~min})$ for measurement of enzyme activity were optimized in aqueous solution. Next, the effect of an organic phase on the enzyme activity was studied by the addition of various solvents with the activity being evaluated after $10 \mathrm{~min}$ of mixing. It was found that by using hexane, the enzyme retained almost $100 \%$ of its
\end{abstract}

\section{Received 18 April 2005; accepted 15 May 2005}

The authors thank the MIUR project FISR-1999 and the EU project BIOCOP for financial support.

Address correspondence to Giuseppe Palleschi, Dipartimento di Scienze e Tecnologie Chimiche, Università di Roma Tor Vergata, Via della Ricerca Scientifica, Rome, Italy. E-mail: giuseppe.palleschi@uniroma2.it 
activity, and this solvent was chosen for further development of the pesticide assay. Hexane was spiked with different concentrations of pesticides and then added to the enzyme aqueous phase. The pesticides were shown to be able to inhibit the enzyme by interaction at the interface between the two solutions. The degree of inhibition obtained with increasing amounts of pesticide was evaluated. A $50 \%$ inhibition was observed for a paraoxon solution of $9 \times 10^{-7} \mathrm{M}$.

Keywords: Acetylcholinesterase, paraoxon, Ellman's method, organic solvent, heavy metals

\section{INTRODUCTION}

Pesticides are among the most important environmental pollutants because of their significant presence in the environment. The use of pesticides in agriculture has progressively increased since World War II with a concomitant increase in world food production. In this context, industrial emission of pesticides during their production, and more importantly, the presence of residues of these chemicals and their metabolites in food, water, and soil, has become a problem for society at large (FAO 1993). Among the many methods reported for pesticide detection, chromatographic methods, such as high-performance liquid chromatography (HPLC) and gas chromatography (GC), are used as reference methods (American Public Health Association 1998; Liska and Slobodnik 1996). Thus, enzymatic methods have been adopted as an alternative to classical methods (GC, HPLC) for faster and simpler detection of some environmental pollutants (Preininger and Wolfbeis 1996; Bagirova et al. 2001).

The use of cholinesterase enzymes for inhibition-based determination of pollutants has shown great promise for environmental screening analysis (Bernabei et al. 1993; Cremisini et al. 1995; Hart et al. 1997). Acetylcholinesterase or butyrylcholinesterase are irreversibly inhibited by organophosphorous and carbamate pesticides and reversibly inhibited by heavy metals (Danzer and Schwedt 1996; Kukla et al. 1999; Marquis and Lerrick 1982), and a comparison of the activity of acetylcholinesterase (AchE) before and after exposure to environmental samples can provide an evaluation of the pollution level. The measurement of enzymatic activity can be accomplished by electrochemical (Bernabei et al. 1993; Cremisini et al. 1995; Solè et al. 2003), chemiluminescent (Danet et al. 2000), or spectrophotometric methods (Pogačnik and Franko 1999; Ellman 1959).

In the most commonly used spectrophotometric assay method for pesticide detection, acetylthiocholine is used as substrate of AchE, and the production of thiocholine is measured by Ellman's method (1959), as shown in Equation (1). DTNB (5,5'-dithiobis-(2-nitrobenzoic acid) reacts with thiocholine to give TNB, 2-nitro-5-thiobenzoic acid, a yellow product 
with an maximum absorption at $412 \mathrm{~nm}$.

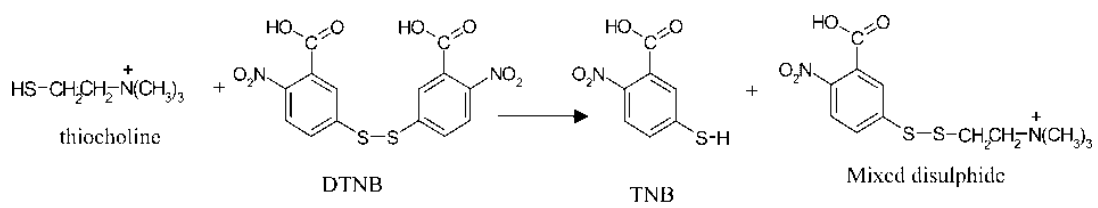

However, it should be pointed out that this method could be negatively affected by the presence of heavy metals in the sample. Given the high affinity of thiols for heavy metals (Majid et al. 2002; Kreżel et al. 2001; Friedman 1973), the thiocholine produced by the enzymatic reaction could in fact react with heavy metals present in the sample solution. Such metal binding is expected to interfere with the reaction described in Equation (1) and, thus, would lead to an overestimation of pesticide level when this spectrophotometric determination of AchE activity is used. To avoid this problem, a separation step would seem to be required in which pesticides are first extracted into an organic phase. This would eliminate the presence in the sample solution of heavy metals and other water-soluble enzymatic inhibitors such as fluoride (Tran-Minh et al. 1990) and hyplochlorite (Soldatkin et al. 1997), given their low solubility in organic solvents.

A major problem relates to the effect of the organic solvents normally used for pesticide extraction on acetylcholinesterase activity because many of these solvents are known to inhibit the AchE reaction (Campanella et al. 1999; Wilkins et al. 2000). At the same time, liquid extraction with organic solvents (Dean and Xiong 2000; Babic et al. 1998; U.S. EPA) or solidphase extraction (SPE) (Vassilakis et al. 1998; Mena et al. 2002; Viana et al. 1996) followed by chromatographic methods (gas chromatography or highperformance liquid chromatography) are the procedures usually adopted for pesticide determination. Extraction steps are routinely used for the measurement of pesticides from real samples and, in fact, fruit, vegetable, and cereal samples are always blended with organic solvents to achieve an efficient extraction of pesticides. Organic solvents are also used in the case of liquid samples (i.e., fruit juices, wine, and water) to achieve a sort of preconcentration of the analyte (Ahmed 2001), given that pesticides are usually much more soluble in organic solvents than in water.

Several articles have shown the possibility of circumventing the problem of enzyme inactivation by constructing inhibition-based enzyme biosensors operating in different types of nonaqueous solvents (Adeyoyu et al. 1995; Adeyoyu et al. 1994; Barcelo et al. 1995; Campanella et al. 1998). However, AchE has demonstrated very low activity in organic solvents (Campanella et al. 1999; Wilkins et al. 2000; Mionetto et al. 1994). Successful AchE determination with organic solvents has been demonstrated only by use of an organic solvent saturated with water (Wilkins et al. 2000; Mionetto et al. 1994), but there was still a considerable loss in enzyme activity. 
The aim of our work was to develop a practical assay for pesticides based on the use of Ellman's method to determine their inhibition of acetylcholinesterase activity. The strategy involved the use of two immiscible phases, an organic phase containing the pesticides and an aqueous phase containing the enzyme so that the pesticides would be extracted into the aqueous phase by virtue of their binding to the active site of the AchE at the interface between the two phases. In the present article (1) the direct effect of heavy metals on the reaction in Ellman's method and (2) the effect of organic solvents on enzymatic activity have been fully investigated. Finally, optimized conditions were defined to determine the inhibition of AchE activity by pesticides dissolved in the organic phase, thus minimizing the potential interference of heavy metals through their reaction with either the enzyme or the thiocholine produced.

The results showed that this approach provides an easy and time-efficient assay that enabled the detection of paraoxon with detection limits that were of the same order of magnitude as those found for the assay in aqueous solutions. Moreover, the interference by heavy metals was avoided.

\section{EXPERIMENTAL}

\section{Apparatus and Reagents}

For spectrophotometric measurements, an Unicam 8625 UV/VIS spectrophotometer was used.

All chemicals from commercial sources were of analytical grade.

Thiocholine measurements were carried out by using the classical Ellman's method based on the reaction between thiocholine and DTNB (5,5'-dithiobis-(2-nitrobenzoic acid). Acetylcholinesterase (AchE) from electric eel (EC 3.1.1.7, 244 units/mg), acetylthiocholine chloride, and DTNB were obtained from Sigma (St. Louis, MO). The solution of DTNB $(1 \mathrm{mM})$ used in the experiment was prepared in phosphate buffer $10 \mathrm{mM}$, $\mathrm{pH}$ 7.0. For the measurement of reaction between thiocholine and heavy metals, aqueous solutions were prepared with silver, cadmium, lead and nickel nitrates, and ferric(II) sulfate from Carlo Erba (Milano); cupric sulfate, mercury chloride, zinc sulfate, aluminium potassium sulfate, manganese chloride, and arsenic acid (sodium salt) from Sigma; and iron(III) chloride from Fluka. Measurement of the effect of the solvent on AchE was carried out by using hexane and toluene from Carlo Erba (Milano); octanol, cyclohexane, and chloroform from Sigma; iso-hexane PESTANAL $^{\circledR}$ from Riedel de Haen; dichloromethane from Aldrich; and ciclohexanone from Fluka. The measurement of enzyme inhibition was carried out by using paraoxon (O,O-diethyl-O-(-4-nitro-phenylphosphate) obtained from Sigma. Stock solutions $(4.5 \mathrm{mM})$ of paraoxon was prepared 
in ethanol. Different concentrations of pesticides were obtained by diluting the stock solution in hexane.

\section{Measurement of Thiocholine}

Thiocholine was produced enzymatically by using AchE as enzyme and acetylthiocholine as substrate (because thiocholine is not commercially available). For this purpose, $1 \mathrm{~mL}$ of acetylthiocholine solution $1 \mathrm{M}$ was prepared in phosphate buffer $0.1 \mathrm{M}(\mathrm{pH}=8)$, and 100 units of AchE were added to this solution. After $1 \mathrm{~h}$, the concentration of thiocholine produced by AchE was estimated spectrophotometrically by Ellman's method. For this purpose, $900 \mu \mathrm{L}$ of phosphate buffer solution $(0.1 \mathrm{M}, \mathrm{pH}=8), 100 \mu \mathrm{L}$ of $0.1 \mathrm{M}$ DTNB, and $5 \mu \mathrm{L}$ thiocholine solution (diluted $1: 100$ in water) were put in a cuvette. Absorbance was measured at different times, and the real concentration was evaluated by using the Lambert-Beer law with the known molar extinction coefficient of TNB $\left(\varepsilon=13,600 \mathrm{M}^{-1} \mathrm{~cm}^{-1}\right)$ (Ellman 1959).

After $1 \mathrm{~h}$, the hydrolysis reaction of acetylthiocholine is completed, and $1 \mathrm{~mL}$ solution of $1 \mathrm{M}$ thiocholine is obtained. The solution is stable for 1 day at $4{ }^{\circ} \mathrm{C}$.

\section{Reaction Between Thiocholine and Heavy Metals}

To study the reaction between thiocholine and heavy metals, $900 \mu \mathrm{L}$ of phosphate solution $(0.1 \mathrm{M}, \mathrm{pH}=8), 10 \mu \mathrm{L}$ of thiocholine solution $\left(1 \times 10^{-3} \mathrm{M}\right)$ and $10 \mu \mathrm{L}$ of heavy metal solutions of various concentrations were added to the same cuvette. After $10 \mathrm{~min}, 100 \mu \mathrm{L}$ of $0.1 \mathrm{M}$ DTNB were added, and the TNB produced was evaluated at $412 \mathrm{~nm}$. The absorbance decrease, relative to the solution without heavy metal, was then correlated to the percentage of thiocholine that has reacted with heavy metal cations as follows:

$$
\mathrm{R} \%=\left(\mathrm{A}_{0}-\mathrm{A}_{\mathrm{R}}\right) / \mathrm{A}_{0}
$$

where $\mathrm{R} \%$ is $\%$ of thiocholine that reacts with heavy metals, $\mathrm{A}_{0}$ is absorbance obtained with thiocholine solution alone, and $A_{R}$ is absorbance obtained for thiocholine in the presence of heavy metals.

\section{Measurement of the Enzymatic Activity in Aqueous Solution}

The measurement of AchE activity in aqueous solution was carried out by using $5 \mathrm{~mL}$ of phosphate solution $(0.1 \mathrm{M}, \mathrm{pH} 8.0)$ containing a known amount of AchE. This solution $(900 \mu \mathrm{L})$ and $10 \mu \mathrm{L}$ of $0.1 \mathrm{M}$ acetylthiocholine were put in a cuvette. The absorbance measurement was performed $20 \mathrm{~min}$ 
after the addition of the substrate (acetylthiocholine) adding $100 \mu \mathrm{L}$ of $0.1 \mathrm{M}$ DTNB in the same cuvette. The enzymatically generated thiocholine reacts with DTNB to give the yellow TNB.

\section{Measurement of Pesticide in Aqueous Solution}

For determination of pesticide inhibition, the same procedure as described above was used, except that the aqueous solution was spiked with different amounts of paraoxon and carbofuran. The degree of inhibition was calculated as follows:

$$
\mathrm{I} \%=\left(\mathrm{A}_{0}-\mathrm{A}_{\mathrm{i}}\right) / \mathrm{A}_{0}
$$

where $\mathrm{I} \%$ is $\%$ of inhibition, $\mathrm{A}_{0}$ is absorbance obtained in phosphate buffer, and $A_{i}$ is absorbance obtained for phosphate buffer spiked with pesticide.

\section{Measurement of the Effect of Organic Solvents on Enzyme Activity}

To evaluate the effect of the organic solvent on the enzyme activity, $5 \mathrm{~mL}$ of phosphate buffer solution $(0.1 \mathrm{M}, \mathrm{pH} 8.0)$ containing a known amount of AchE was mixed with $5 \mathrm{~mL}$ of an organic solvent. The two immiscible solutions were then gently stirred for $10 \mathrm{~min}$ (incubation time) (see Scheme 1a). Nine hundred microliters were then taken from the aqueous phase, which contained the enzyme. The sample was put in a cuvette, and the residual enzymatic activity was evaluated by using the procedure described above. Inactivation of enzyme by exposure to organic solvent was evaluated by using Equation (2) where I\% is \% of enzyme inactivation due to organic solvent, $A_{0}$ is absorbance obtained in aqueous solution, and $A_{i}$ is

(a)
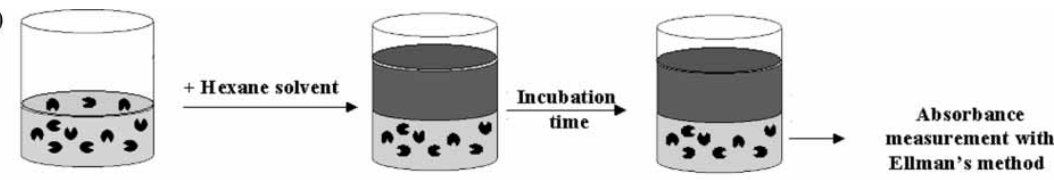

(b)
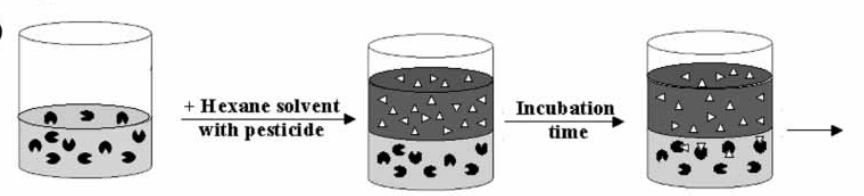

Absorbance measurement with Enzyme solution Ellman's method

Scheme 1. Procedure for the evaluation of the effect of the organic solvent on enzyme activity (a) and for the measurement of pesticide (b). "sen: Enzyme solution (AChE, $7 \mathrm{mU} \mathrm{mL}^{-1}$ ) in phosphate buffer $(0.1 \mathrm{M}, \mathrm{pH} 8.0) . \therefore \therefore$ : Pesticide solution (organic solvent hexane).

: Organic solvent. 
absorbance obtained for enzyme in aqueous solution in contact with organic solvent for $10 \mathrm{~min}$ (Scheme 1a).

\section{Measurement of Inhibition by Pesticide Present in Organic Solvent}

For pesticide measurements, the same procedure described above was used, except that the organic solvent (hexane) was spiked with different amounts of paraoxon (Scheme 1b) or carbofuran, and the degree of the inhibition was calculated by using Equation (2) where $\mathrm{I} \%$ is $\%$ of inhibition, $\mathrm{A}_{0}$ is absorbance obtained by using hexane without pesticide (Scheme 1a), and $A_{i}$ is absorbance obtained by using hexane spiked with pesticide (Scheme 1b).

\section{RESULTS AND DISCUSSION}

\section{Reaction Between Heavy Metals and Thiocholine}

The high affinity of thiols for heavy metals has been widely reported in the literature (Kreżel et al. 2001; Friedman 1973; Troger 2001; Disbudak et al. 2002). The complexation between some thiols such as penicillamine and cysteine with heavy metals has been studied for several applications in pharmacological and enviromental areas (Chipasa 2003; Fisher 2002). Despite this, to our best knowledge, a study concerning the reaction between thiocholine and heavy metals has not been reported in the literature. In this work, thiocholine complexation with heavy metals has been evaluated. As already pointed out in the introduction, heavy metal cations could represent a major interference in the measurement of thiocholine produced by AchE when enzyme inhibition is used as a means for pesticide detection. Figure 1 shows the concentration of different heavy metals that decreases the thiocholine signal by $15 \%$. The choice of heavy metals to analyze was made by considering their presence in the environment. This study shows that most of the metal cations, usually present in aqueous samples, react with thiocholine greatly affecting its spectrophotometric measurement. Furthermore, this decrease is inversely proportional to thiocholine concentration (results not shown). The presence of metal ions in the sample could in fact not only act as a inhibitor of acetylcholineterase but also react with thiocholine enzymatically produced. This could lead to the wrong conclusion that heavy metals act as competitive inhibitors when Ellman's method is accomplished for acetylcholinestearase inhibition studies (Stoytcheva 2002).

The extent of the reaction between the heavy metals and thiocholine is regulated by the affinity of thiocholine for the heavy metal and the stoichiometry of the thiocholine-heavy metal complex. For example, to observe a $15 \%$ absorbance decrease, a lower concentration of $\mathrm{Hg}^{2+}$ is required relative to $\mathrm{Zn}^{2+}$ or $\mathrm{Ni}^{2+}$, which are known to be bound by thiols with a lower affinity. In Fe, with the two different oxidation states, the different con- 


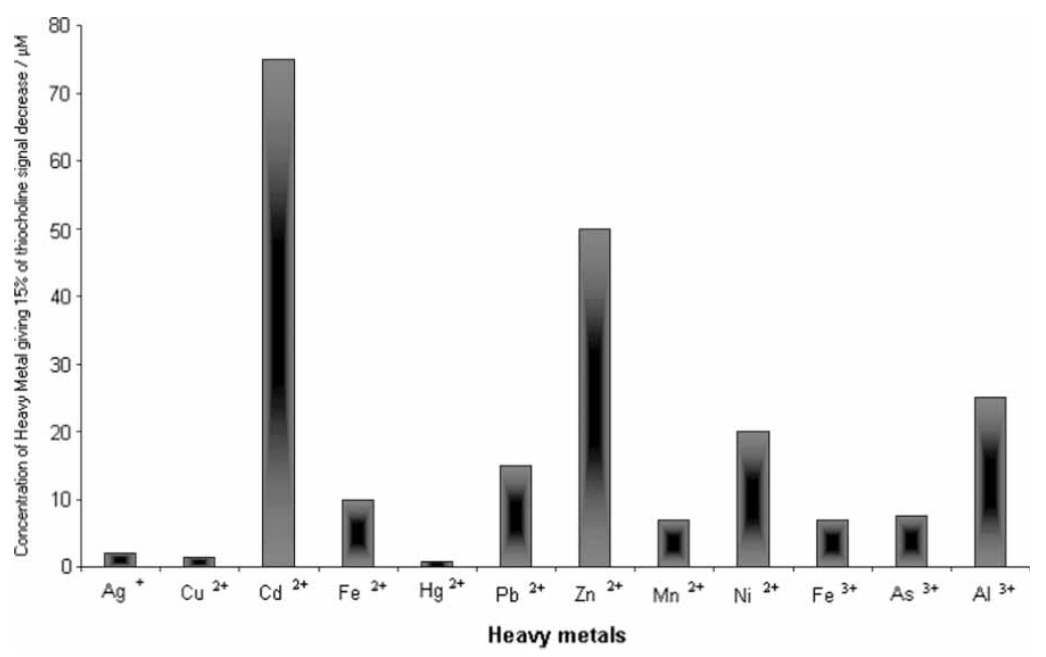

Figure 1. Concentrations of different heavy metals cations giving a decrease of $15 \%$ of thiocholine signal. Thiocholine concentration $1 \times 10^{-5} \mathrm{M}$. Phosphate buffer $0.1 \mathrm{M}$, $\mathrm{pH}=8$.

centration for a $15 \%$ absorbance decrease is accounted for the ability of $\mathrm{Fe}^{2+}$ to react with only two molecules of thiocholine, whereas $\mathrm{Fe}^{3+}$ can react with three molecules of thiocholine.

In general, thiocholine is more strongly bound by $\mathrm{Hg}^{2+}, \mathrm{Cu}^{2+}$, and $\mathrm{Ag}^{+}$. The concentration of $\mathrm{Hg}^{2+}$ and $\mathrm{Ag}^{+}$necessary for $15 \%$ signal decrease is higher than the normal concentrations of these heavy metals in aqueous samples. This demonstrates that $\mathrm{Hg}^{2+}$ and $\mathrm{Ag}^{+}$could be a source of error for inhibition-based pesticide assay.

On the other hand, $\mathrm{Cu}^{2+}$ presents the biggest problem in pesticide analysis because of its high concentration in aqueous samples. The maximum admissible concentration of copper in drinking water is in fact $20 \mu \mathrm{M}$ (American Public Health Association 1998), whereas a much lower amount, $1.4 \mu \mathrm{M}$, is sufficient for a $15 \%$ decrease of the thiocholine signal. This result shows that any method based on AchE inhibition, with the measurement of thiocholine, being used to assess the presence of pesticides, requires a separation between pesticide and heavy metals. The method proposed here attempts to overcome this problem by allowing the measurement of pesticide contained in an organic solvent with an enzymatic method.

\section{Principle of the Method}

The approach is to have the pesticide interact with the enzyme at the interface between an organic and an aqueous phase as illustrated in Scheme 1. The AchE is solubilized in a phosphate buffer solution, which is placed in 
contact with an equal amount of an organic solvent containing the pesticide to be measured. The solutions are stirred during a fixed incubation time. The stirring facilitates the interaction enzyme-pesticide by increasing the interface and mixing the respective components in solution.

Given that virtually all organophospate and carbamate pesticides inhibit AchE by binding irreversibly to a hydroxyl group at the catalytic center, this reaction could have the effect of extracting the pesticide into the aqueous phase. The solubility of pesticides in aqueous solutions is usually very low, thus, the equilibrium between the two phases almost completely favors the organic solvent. However, at the interface, AchE in the aqueous phase can react with the pesticide in organic solvent, thus removing it from the equilibrium. This allows a larger amount of pesticide to be transferred into the aqueous phase through the irreversible binding to the enzyme. For this reason, it can be said that the enzyme extracts the pesticide from the organic solvent.

After a defined period of time, the residual enzyme activity in the aqueous phase is measured by Ellman's method (1959), afterward this phase is separated from the organic one.

\section{Characterization of Enzyme Activity}

To achieve the lowest detection limit for pesticide measurements, it was first necessary to determine the concentration of enzyme, amount of substrate, and the incubation time (reaction time between enzyme and pesticide) that gave optimal results for AchE in aqueous solution, without any exposure to organic solvent.

The first parameter to be optimized was the concentration of the enzymatic substrate (i.e., acetylthiocholine). Figure 2 shows the relation between the degree rate of reaction and the concentration of acetylthiocholine; $1 \mathrm{mM}$ is the lowest concentration that gives the rate near the maximum rate observed at saturating substrate. This concentration was selected for the rest of the work. It is also possible from this plot to determine the MichaelisMenten $\left(\mathrm{K}_{\mathrm{M}}\right)$ constant for acetylthiocholine, which is $0.22 \pm 0.05 \mathrm{mM}$. The $\mathrm{K}_{\mathrm{M}}$ for the natural substrate (acetylcholine) is $0.095 \mathrm{mM}$ (Biochemica Information 1987), demonstrating the obviously higher affinity of the enzyme for its natural substrate.

By using the previously chosen substrate concentration $(1 \mathrm{mM})$ with an enzyme concentration of $7 \mathrm{mU} \mathrm{mL}^{-1}$, reaction time has been optimized. Under these conditions, the thiocholine production (absorbance) is linearly related to the reaction time $(y=-0.024+0.023 x$, where $y$ is the absorbance and $\mathrm{x}$ are the minutes of the reaction time). The detection limit is strictly related to the reaction time, because longer time of enzymatic reaction results in higher production of thiocholine. On the other hand, for a screening method, the time needed to reach the final result should always be as short as 


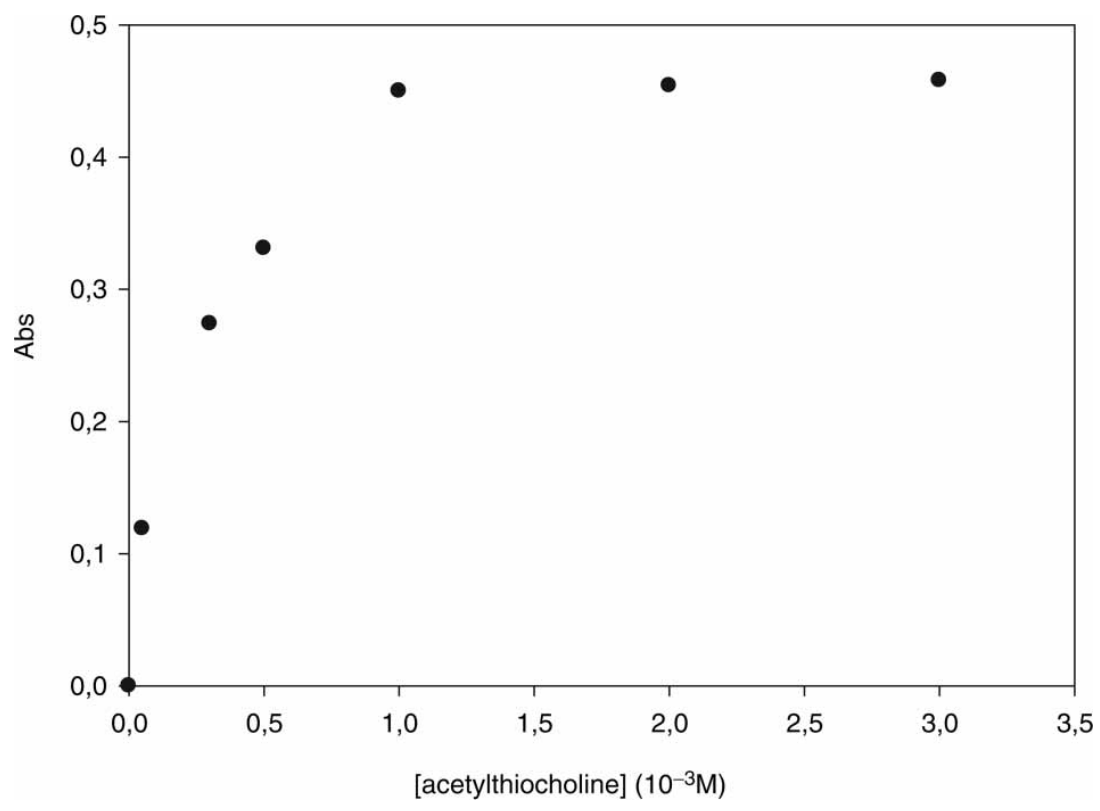

Figure 2. Optimization of substrate concentration. Incubation time $=10 \mathrm{~min}$. Reaction time $=20 \mathrm{~min}$. Concentration of enzyme $=7 \mathrm{mU} \mathrm{mL}^{-1}$.

possible; consequently, $20 \mathrm{~min}$ were chosen as a compromise between a reasonable time of analysis and attainment of a final absorbance value near 0.4.

Finally, the enzyme concentration was optimized. This parameter is also an important factor in determining the final detection limit. The absorbance vs. enzyme concentration obtained with the previously optimized experimental parameters (reaction time $20 \mathrm{~min}, 1 \mathrm{mM}$ substrate concentration) shows a linear correlation $(\mathrm{y}=0.041+0.067 \mathrm{x}$, where $\mathrm{y}$ is absorbance and $\mathrm{x}$ are units of enzyme) in the range studied $\left(3-9 \mathrm{mU} \mathrm{mL}^{-1}\right)$. It is desirable to use the lowest concentration of enzyme that gives an appreciable production of thiocholine, because this provides for a higher sensitivity to the inhibitor. With an enzyme concentration of $7 \mathrm{mU} \mathrm{mL}^{-1}$, it is possible to reach a value of absorbance near 0.4 , after $20 \mathrm{~min}$ from the injection of substrate. This concentration of enzyme, $1 \mathrm{mM}$ of substrate and $20 \mathrm{~min}$ of enzymatic reaction, were then chosen to allow a measurement of the degree of enzyme inhibition with a sufficient precision.

\section{Effect of Different Organic Solvents on Enzyme Activity}

Finding conditions for an efficient extraction of pesticides from organic solvent by cholinesterase enzyme (see Scheme 1) was the objective of the next experiments. In this perspective, the choice of the organic solvent has 
to be made by considering two parameters: (1) the ability of the organic solvent to extract pesticides from real samples and (2) the effect of the organic solvent on enzyme activity.

The organic solvents tested were then chosen because of their different structures and because of their common characteristic of very high insolubility in aqueous solution (Table 1). An extremely low solubility is in fact an essential requirement for the organic solvent; this would prevent the mixing between the enzyme and organic solution, which could have a dramatic effect on enzyme activity and thus interfere with the measurement of the degree of inhibition. In addition, the study of organic solvents with different structures could give a clearer evaluation of the mechanism of interaction between organic solvent and enzyme.

For these preliminary experiments, an incubation time of $10 \mathrm{~min}$ was chosen on the basis of previous studies (Ricci et al. 2004). The effect of the organic solvent on enzyme activity was evaluated as described in the experimental section (Scheme 1). Table 1 summarizes the results obtained for the

Table 1. Effect on enzyme activity of different organic solvents

\begin{tabular}{|c|c|c|c|}
\hline Organic solvent & Structure & $\begin{array}{l}\text { Solubility in } \\
\text { water }(\mathrm{g} / \mathrm{L})\end{array}$ & $\begin{array}{c}\text { Residual } \\
\text { activity }^{a}(\%)\end{array}$ \\
\hline Hexane & $\mathrm{CH}_{3}\left(\mathrm{CH}_{2}\right)_{4} \mathrm{CH}_{3}$ & Insoluble & 100 \\
\hline Octanol & $\mathrm{CH}_{3}\left(\mathrm{CH}_{2}\right)_{6} \mathrm{CH}_{2} \mathrm{OH}$ & Insoluble & 95 \\
\hline $\begin{array}{l}\text { Iso-hexane } \\
\text { PESTANAL }\end{array}$ & isomer mixture & Insoluble & 100 \\
\hline Cyclohexane & & 0.052 & 81 \\
\hline Chloroform & $\mathrm{CHCl}_{3}$ & 7.42 & 71 \\
\hline Dichloromethane & $\mathrm{CH}_{2} \mathrm{Cl}_{2}$ & 20 & 49 \\
\hline Toluene & & 0.67 & 47 \\
\hline Cyclohexanone & & 100 & 0 \\
\hline
\end{tabular}

\footnotetext{
${ }^{a}$ Average RSD $\%=10 \%$.
}

Concentration of enzyme $=7 \mathrm{mU} \mathrm{mL}^{-1}$. Incubation time $=10 \mathrm{~min}$. Acetylthiocholine concentration $=1 \mathrm{mM}$. Reaction time $=20 \mathrm{~min}$. See text and scheme $1 \mathrm{a}$ for details. 
organic solvents tested. In addition to the residual activity of the esterase, value of the solubility in water is also given. It is evident that there is a relation between solubility in water and residual activity. The use of organic solvents, which have higher solubility, such as cyclohexanone or dichloromethane, resulted in low residual activity of AchE (0\% and 49\%, respectively), thus demonstrating an inhibiting effect on enzymatic activity. With the organic solvents, which are completely insoluble, such as hexane or octanol, the residual activity of esterase was not or slightly reduced (100\% and $95 \%$, respectively).

On the basis of these results, it appears that the solubility of the organic solvent can affect the optimum condition of the enzyme activity in phosphate buffer, significantly decreasing its ability to hydrolyze substrates. Only toluene seems to not obey this behavior. Despite its very low solubility in water, toluene results in a strong inhibition of AchE (ca. 47\% of residual activity). The effect of toluene on enzymatic activity can be probably explained by considering another factor. The active site of AchE is at the bottom of a deep and narrow cleft that penetrates halfway into the enzyme structure and becomes wider at its base. Fourteen aromatic residues line a substantial portion of the cleft surface (Sussman et al. 1991). The high degree of inhibition observed in toluene is probably due to a direct interaction between the aromatic residues found in the cleft and the aromatic portion of toluene, as already demonstrated for other aromatic compounds (i.e., calixarenes) (Evtugyn et al. 2002).

The organic solvent that gave the best results in terms of residual activity was hexane (100\% of residual activity). However, further studies showed that inactivation of AchE increases strongly with increase in incubation time. In fact, after 30 and $60 \mathrm{~min}$ with hexane, the residual activity fell to $25 \%$ and $0 \%$, respectively. The optimum conditions for pesticide determination were then chosen: 10 min for incubation time and hexane as organic solvent. This choice also takes into account the wide use of hexane for the extraction of chemical contaminants from real samples (Kumazawa and Suzuki 2000; Colume et al. 2001; Jimenez et al. 2000; Zayed et al. 1998). Finally, paraoxon was selected as standard pesticide for this preliminary study.

\section{Measurement of Inhibition by Paraoxon}

A preliminary study with paraoxon dissolved in organic solvent to demonstrate the enzyme ability to extract the pesticides from nonaqueous solvent has been performed. For this purpose, an organic solution (hexane) spiked with $1.8 \times 10^{-6} \mathrm{M}$ of pesticide was used. In the first experiments, the organic solvent containing the pesticides was put in contact for $10 \mathrm{~min}$ with aqueous solution in which the enzyme was dissolved. Then, the enzyme residual activity was measured as described in the experimental section. In a successive experiment, the organic solution containing the pesticide was 
put in contact with aqueous solution without enzyme. After $10 \mathrm{~min}, 900 \mu \mathrm{L}$ of aqueous solution were put in a cuvette, and the enzyme was added. After $10 \mathrm{~min}$ (incubation time), acetylthiocholine was added, and the enzyme residual activity was measured as described in the experimental section. In the first case, the enzyme inhibition obtained was $75 \%$, whereas in the second experiment, a $15 \%$ of enzyme inactivity, probably due to the pesticide spontaneously passed in the aqueous solution, has been observed. This result shows that the enzyme dissolved in aqueous phase markedly increases the extraction of pesticides into organic phase. The calibration curve for paraoxon dissolved in hexane is shown in Figure 3 (see Experimental section and Scheme 1 for details).

At a concentration of paraoxon of $1.8 \times 10^{-7} \mathrm{M}$, an inhibition of about $30 \%$ could be observed. The curve (Figure 3 ) seems to be linear up to $2.9 \times 10^{-6} \mathrm{M}$, which corresponds to $90 \%$ of inhibition. Inhibition $(50 \%)$ was obtained with $2 \times 10^{-7} \mathrm{M}$ and $9 \times 10^{-7} \mathrm{M}$ of paraoxon present in aqueous solution and aqueous/organic solution, respectively. The different degrees of inhibition are due to the different reactions of enzyme at the interface in aqueous/organic solution. The sensitivity of this method observed in this preliminary study is lower than the method based on esterase inhibition in aqueous solution because the reaction between

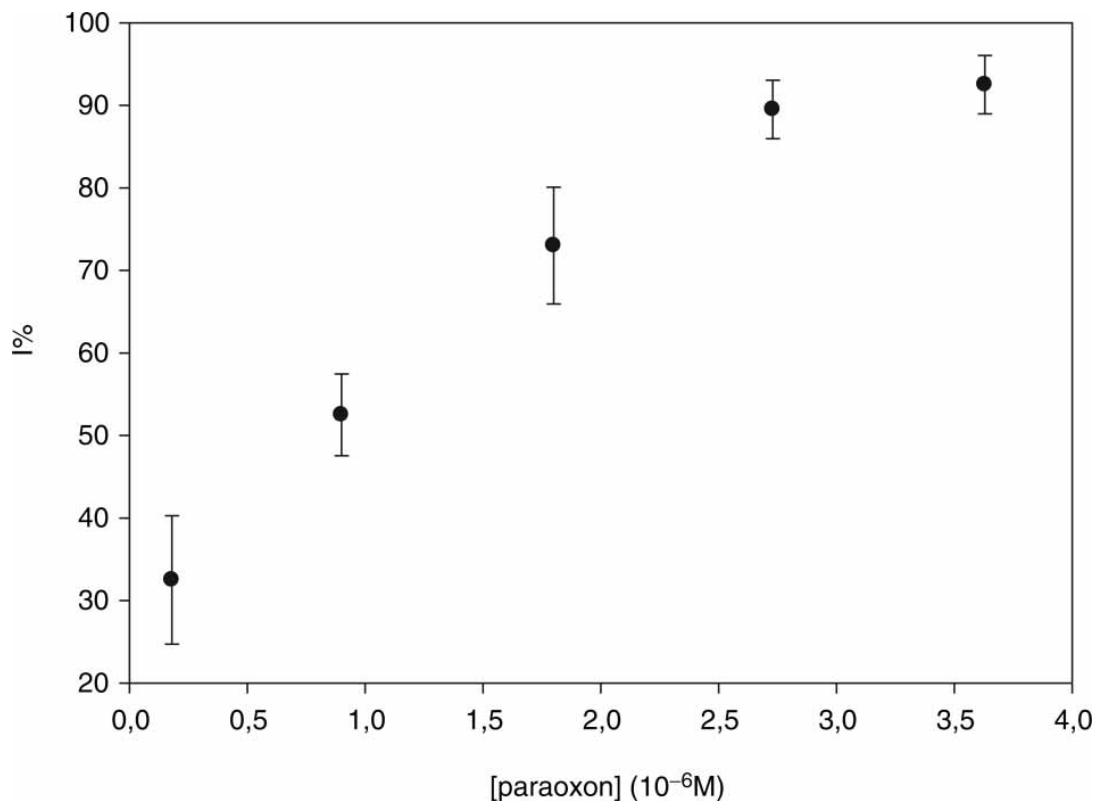

Figure 3. Calibration curve for paraoxon. Incubation time $=10 \mathrm{~min}$. Reaction time $=20 \mathrm{~min}$. Concentration of enzyme $=7 \mathrm{mU} \mathrm{mL}^{-1}$. Acetylthiocholine concentration $=1 \mathrm{mM}$. See text and Scheme $1 \mathrm{~b}$ for details. 
enzyme and pesticide is greatly favored in aqueous solution than at the interface aqueous/organic solution, and in the time allowed for the reaction, the enzyme cannot extract the total amount of pesticides present in organic solvent. However, we should keep in mind that pesticide can be concentrated by using liquid extraction with organic solvent.

\section{CONCLUSIONS}

The study of the reaction between thiocholine and heavy metals has been accomplished to demonstrate that some heavy metal cations, usually present in samples, could have a strong influence in the measurement of pesticides, limiting the reaction of thiocholine with DTNB and thus overestimating the pesticide concentration. This result shows that in any method based on the use of AchE with final measurement of thiocholine for pesticide detection, a separation between pesticide and heavy metals is necessary.

A novel method for the detection of pesticides by inhibition of AchE has been developed. It makes use of two immiscible phases in which the pesticide (organic phase) and the enzyme (aqueous phase) are solubilized. The enzyme (AchE) is then able to extract the pesticide at the aqueous/organic interface by an irreversible binding reaction. This results in an inhibition of the enzyme, which can then be related to pesticide concentration. An inhibition of $50 \%$ has been observed with $9 \times 10^{-7} \mathrm{M}$ of paraoxon.

This method seems very promising as a biosensing test for screening pesticides in environmental samples. Specifically, the use the two immiscible phases with an appropriate choice of organic solvent circumvents the intractable problem of the inactivation of cholinesterase enzymes by organic solvents. At the same time, the pesticide analyte is introduced into the assay system in an organic phase like (or compatible) that resulting from the standard extraction methods. In this way, the presence of heavy metals, or other water-soluble enzyme inhibitors, which could interfere with the inhibition-based assay, is largely avoided.

\section{REFERENCES}

Adeyoyu, D., Iwuoha, E., and Smith, M.R. 1994. Kinetic study of the inhibitory effects of methyl isothiocyanate on a peroxidase-modified platinum electrode in nonaqueous media. Anal. Lett., 27: 2071-2081.

Adeyoyu, D., Iwuoha, E., and Smith, M.R. 1995. Reactivities of amperometric organic phase peroxidase-modified electrodes in the presence and absence of thiourea and ethylenthiourea as inhibitors. Anal. Chim. Acta, 305: 57-64.

Ahmed, F.E. 2001. Analyses of pesticides and their metabolites in foods and drinks. Trends Anal. Chem., 20: 649-655.

Babic, S., Petrovic, M., and Kastelan-Macan, M. 1998. Ultrasonic solvent extraction of pesticides from soil. J. Chromatogr. A, 823: 3-9. 
Bagirova, N.A., Shekhovtsova, T.N., and Van Huystee, R.B. 2001. Enzymatic determination of phenols using peanut peroxidase. Talanta, 55: 1151-1164.

Barcelo, D., Lacorte, S., and Marty, J.L. 1995. Validation of an enzymatic biosensors with liquid chromatography for pesticide monitoring. Trends Anal. Chem., 14: 334-340.

Bernabei, M., Chiavarini, S., Cremisini, C., and Palleschi, G. 1993. Anticholinesterase activity measurement by a choline biosensor: Application in water analysis. Biosens. Bioelectron., 8: 265-271.

Biochemica Information. 1987. Boehringer Mannheim Biochemicals Publ.: Indianapolis, IN, 4-5.

Campanella, L., De Luca, S., Sammartino, M.P., and Tomassetti, M. 1999. A new organic phase enzyme electrode for the analysis of organophosphorus pesticides and carbamates. Anal. Chim. Acta, 385: 59-71.

Campanella, L., Favero, G., Sammartino, M.P., and Tomassetti, M. 1998. Further development of catalase, tyrosinase and glucose oxidase based organic phase enzyme electrode response as a function of organic solvent properties. Talanta, 46: 595-606.

Chipasa, K.B. 2003. Accumulation and fate of selected heavy metals in a biological wastewater treatment system. Waste Menage, 23: 135-143.

Colume, A., Cardenas, S., Gallego, M., and Valcarcel, M. 2001. Semiautomatic multiresidue gas chromatographic method for the screenin of vegetables for 25 organochlorine and pyrethroid pesticides. Anal. Chim. Acta, 436: 153-162.

Cremisini, C., Di Sario, S., Mela, J., Pilloton, R., and Palleschi, G. 1995. Evaluation of the use of free and immobilised acetylcholinesterase for paraoxon detection with an amperometric choline oxidase based biosensor. Anal. Chim. Acta, 311: 273-280.

Danet, A.F., Badea, M., Marty, J.L., and Aboul-Enein, H.Y. 2000. Flow analysis for determination of paraoxon with the use of an immobilised acethylcholinesterase reactor and a new type of chemiluminescent reaction. Biopolymers (Biospectroscop.), 57: $37-42$.

Danzer, T. and Schwedt, G. 1996. Chemometric methods for the development of a biosensor system and the evaluation of inhibition studies with solutions and mixtures of pesticides and heavy metals. Part 1. Development of an enzyme electrodes system for pesticide and heavy metal screening using selected chemometric methods. Anal. Chim. Acta, 318: 275-286.

Dean, J.R. and Xiong, G. 2000. Extraction of organic pollutants from environmental matrices: Selection of extraction tecniques. Trends Anal. Chem., 19: 553-563.

Disbudak, A., Bektas, S., Patir, S., Genc, O., and Denizli, A. 2002. Cysteine-metal affinity chromatography: Determination of heavy metal adsorption properties. Separ. Purif. Technol., 26: 273-281.

Ellman, G.L. 1959. Tissue sulfhydryl groups. Arch. Biochem. Biophys., 82: 70-77.

Evtugyn, G.A., Budnikov, G.K., and Nikol'skava, E.B. 2002. Biochemical tests based on stabilized cholinesterase preaprations: New approaches. J. Anal. Chem., 57: 954-959.

FAO. 1993. Agriculture towards 2010. In: C 93/94 Document of 27th Session of the FAO Conference; Rome.

Fisher, K. 2002. Removal of heavy metals from soil components and soil by natural chelating agents. Part I. Displacement from clay minerals and peat by L-cysteine and L-penicillamine. Water, Air, Soil Pollut., 137: 267-286.

Friedman, M. 1973. The Chemistry and Biochemistry on the Sulphydryl Group in Amino Acids, Peptides and Proteins. 1st ed. Pergamon Press: Oxford, 25-50. 
Hart, A.L., Collier, W.A., and Janssen, D. 1997. The response of screen-printed enzyme electrodes containing cholinesterase to organo-phosphates in solution and from commercial formulation. Biosens. Bioelectron., 12: 645-654.

Jimenez, J.J., Bernal, J.L., del Nozal, M.J., Novo, M., Higes, M., and Lorente, J. 2000. Determination of rotenone in raw honey by solid-phase extraction and highperformance liquid chromatography. J. Chromatogr. A, 871: 67-73.

Kreżel, A., Leśniak, W., Jeżowska-Bojczuka, M., Mlynarz, P., Brasun, J., Kozlowski, H., and Bal, W. 2001. Coordination of heavy metals by dithiothreitol, a commonly used thiol group protectant. J. Inorg. Biochem., 84: 77-88.

Kukla, A.L., Kanjuk, N.I., Starodub, N.F., and Shirshov, Y.M. 1999. Multienzyme electrochemical sensor array for determination of heavy metal ions. Sens. Actuat. B, 57: 213-218.

Kumazawa, T. and Suzuki, O. 2000. Separation methods for amino group possessing pesticide in biological sample. J. Chromatogr. B, 747: 241-254.

Liska, I. and Slobodnik, J. 1996. Comparison of gas and liquid chromatography for analysing polar pesticides in water samples. J. Chromatogr. A, 733: 235-258.

Majid, S., El Rhazi, M., Amine, A., and Brett, C.M.A. 2002. An amperometric method for the determination of trace mercury(II) by formation of complexes with L-tyrosine. Anal. Chim. Acta, 464: 123-133.

Marquis, J.K. and Lerrick, A.J. 1982. Noncompetitive inhibition by aluminum, scandium and yttrium of acetylcholinesterase from electrophorus electricus. Biochem. Pharmacol., 31: 1437-1440.

Mena, M.L., Martinez-Ruiz, P., Reviejo, A.J., and Pingarron, J.M. 2002. Molecularly imprinted polymers for on-line preconcentration by solid phase extraction of pirimicarb in water samples. Anal. Chim. Acta, 451: 297-304.

Mionetto, N., Marty, J.L., and Karube, I. 1994. Acetylcholinesterase in organic solvents for the detection of pesticides: biosensor application. Biosens. Bioelectron., 9: 463-470.

Pogačnik, L. and Franko, M. 1999. Determination of organophosphate and carbamate pesticides in spiked samples of tap water and fruit juices by a biosensor with photothermal detection. Biosens. Bioelectron., 14: 569-578.

Preininger, C. and Wolfbeis, O.S. 1996. Disposable cuvette test with integrated sensor layer for enzymatic determination of heavy metals. Biosens. Bioelectron., 11: 981-990.

Ricci, F., Arduini, F., Amine, A., Moscone, D., and Palleschi, G. 2004. Characterisation of Prussian blue modified screen-printed electrodes for thiol detection. J. Electroanal. Chem., 563: 229-237.

Soldatkin, A.P., Gorchkov, D.V., Martelet, C., and Jaffrezic-Renault, N. 1997. New enzyme potentiometric sensor for hypochlorite species detection. Sens. Actuat. B, 43: 99-104.

Solè, S., Merkoci, A., and Alegret, S. 2003. Determination of toxic substances based on enzyme inhibition. Part I. Electrochemical biosensors for the determination of pesticides using batch procedures. Crit. Rev. in Anal. Chem., 33 (2): 9-12.

Standard Methods for Examination of Water and Wastewater. 1998. 20th ed. American Public Health Association: Washington, 6/85-6/90.

Standard Methods for Examination of Water and Wastewater. 1998. 20th ed. American Public Health Association: Washington, 3/71-3/72.

Stoytcheva, M. 2002. Electrochemical evaluation of the kinetic parameters of a heterogeneous enzyme reaction in presence of metal ions. Electroanalysis, 14: 23-927. 
Sussman, J.L., Harel, M., Frolow, F., Oefner, C., Goldman, A., Toker, L., and Silman, I. 1991. Atomic structure of acetylcholinesterase from torpedo californica: A prototypic acetylcholine-binding protein. Science, 253: 872-878.

Tran-Minh, C., Pandey, P.C., and Kumaran, S. 1990. Studies on acetylcholine sensor and its analytical application based on the inhibition of cholinesterase. Biosens. Bioelectron., 5: 461-471.

Troger, M. 2001. $\mathrm{Hg}$ (II) Coordination studies in penicillamine enantiomers by ${ }^{199 \mathrm{~m}} \mathrm{Hg}$ TDPAC. Hyperfine Interact., 136: 673-680.

U.S. Enviromental Protection Agency. Pesticides: Analytical methods and procedures. http://www.epa.gov/oppbead1/methods/ram12b.htm

Vassilakis, I., Tsipi, D., and Scoullos, M. 1998. Determination of a variety of chemical classes of pesticides in surface and ground waters by off-line solid-phase extraction. J. Chromatogr. A, 823: 49-58.

Viana, E., Redondo, M.J., Font, G., and Moltò, J.C. 1996. Disks versus columns in the solid-phase extraction of pesticides from water. J. Chromatogr. A, 733: 267-274.

Wilkins, E., Carter, M., Voss, J., and Ivnitski, D. 2000. A quantitative determination of organophosphate pesticides in organic solvents. Electrochem. Commun., 2: 786-790.

Zayed, S.M.A.D., Farghaly, M., and Mahdy, F. 1998. Effect of commercial processing procedures on carbofuran residues in soybean oil. Food Chem., 62: 265-268. 